\title{
Spatial-Temporal Patterns of Element Concentrations in Xanthoparmelia camtschadalis Transplanted along Roads
}

\author{
Shengju Jia', Xin Zhang1, Qingxue Liu², Qingzhi Chen², Xing Li², Xuemin Pang², \\ Jianjun $\mathrm{Li}^{3}$, Qingfeng Wu${ }^{1}$, Liangcheng $\mathrm{Zhao}^{2 *}$, Huajie Liu ${ }^{1 * *}$ \\ ${ }^{1}$ College of Life Sciences, Hebei University, Baoding, Hebei Province, China \\ ${ }^{2}$ Hebei Research Center for Geoanalysis, Baoding, Hebei Province, China \\ ${ }^{3}$ Baoding Meteorological Bureau, Hebei Province, China
}

Received: 18 July 2018

Accepted: 21 November 2018

\begin{abstract}
Lichen transplantation is a powerful tool for monitoring the deposition of atmospheric elements in areas devoid of native or expected lichens. The foliose lichen Xanthoparmelia camtschadalis (XPc) was transplanted along two busy roads in Hebei, China, and was exposed for 3, 6, 9 and 12 months. Twenty-five elements (Al, Ba, Cd, Ce, Cs, Cu, Fe, La, Mg, Mn, Na, Ni, Pb, Rb, S, Sb, Sc, Sm, Sr, Tb, $\mathrm{Th}, \mathrm{Ti}, \mathrm{Tl}, \mathrm{V}$, and $\mathrm{Zn}$ ) were measured using an inductively coupled plasma mass spectrometer (ICP-MS). The concentrations of all elements were higher in post-exposure samples than in the control, suggesting severe air pollution at the exposure sites. The temporal trends of the lichen $\mathrm{S}$ concentration were similar to those of the atmospheric $\mathrm{SO}_{2}$ concentration. This result indicates that the release of $\mathrm{SO}_{2}$ during the winter heating period elevated the lichen $\mathrm{S}$ concentrations, for which $X P c$ had an integration time of $<3$ months. Metal concentrations peaked after 9-month exposure at exposure sites near roads, whereas they peaked after 12-month exposure at the other sites. This result indicates that the emissions near the roads accelerated the accumulation of metals, for which $X P c$ had an integration time of $>3$ months. Our results confirmed the applicability of $X P C$ for assessing the atmospheric pollution influenced by road emissions in highly polluted regions.
\end{abstract}

Keywords: lichen transplantation, atmospheric deposition, biomonitoring, heavy metals, road pollution

\section{Introduction}

An increasing body of literature has addressed the applicability of lichens as biomonitors of atmospheric

*e-mail: zhao.1.c@163.com

**e-mail: liuhuajie@foxmail.com element deposition [1-3]. These organisms have been regarded as effective bioaccumulators of heavy metals and complex organic pollutants because lichens rely on the atmosphere for nutrients and have high capacities to accumulate and tolerate atmospheric pollutants [1-4].

In China, road traffic is one of the largest sources of emissions of atmospheric pollutants, which have negative effects on human health and the ecosystem 
[5-6]. Monitoring the road emissions, especially heavy metals, is a concern for the country. Lichen transplantation is a suitable method for monitoring road pollution, but this method has not yet been used for this purpose in China.

Lichen transplantation is widely employed at polluted sites that lack native or expected lichens [1, 4]. With this technique, lichens are collected from "background sites" (sites that are lower in atmospheric deposition relative to the exposure sites) and transplanted to the study sites, and then their responses are recorded [7-8]. Lichen transplantation can provide adequate samples in the highly polluted sites devoid of native lichens due to the negative effects of air pollution on the diversity or abundance of lichens [9-10]. This technique can ensure the uniformity of the lichen species because lichen element compositions are often element specific and depend on the lichen species [11-12]. This technique can also provide chances to select the exposure time and monitoring sites. Relevant studies have revealed the accumulation of atmospheric pollutants originating from vehicle emissions, and the suspension of road dust in lichen thalli and have documented the negative effects of atmospheric pollutants on lichen diversity and physiology [1, 8, 13-14].

Xanthoparmelia camtschadalis $(X P C)$ is a promising candidate for transplantation because this lichen can be easily collected intact, and the contamination of the thallus by soil is lower than in other lichen species [15]. $X P C$ is a foliose lichen that is widely distribute in the grassland of northern China. This organism partly attaches to the soil surface when it is young and can be readily dispersed by wind when mature. In the Inner Mongolian grasslands, relevant studies have reported that $X P C$ was less contaminated by soil than other epigeal lichens and can accumulate atmospheric element depositions originating from anthropogenic emissions, especially $\mathrm{Pb}, \mathrm{Zn}$ and $\mathrm{Cd}$ [15].

$X P c$ was collected from the Xilin River Basin in Inner Mongolia and was placed at different distances from the roads in a highly polluted area with complicated sources of air pollution. Twenty-five elements (Al, Ba, $\mathrm{Cd}, \mathrm{Ce}, \mathrm{Cs}, \mathrm{Cu}, \mathrm{Fe}, \mathrm{La}, \mathrm{Mg}, \mathrm{Mn}, \mathrm{Na}, \mathrm{Ni}, \mathrm{Pb}, \mathrm{Rb}, \mathrm{S}, \mathrm{Sb}$, Sc, Sm, Sr, Tb, Th, Ti, Tl, V, and Zn) were measured. We attempted to address the question: do the elements in $X P C$ increase at a higher rate in sites near the roadside than in sites far from the roads?

\section{Materials and Methods}

\section{Sample Collection}

Lichen samples were collected from the Xilin River Basin $\left(43^{\circ} 33^{\prime}-43^{\circ} 42^{\prime} \mathrm{N}, 116^{\circ} 37^{\prime}-116^{\circ} 51^{\prime} \mathrm{E}\right)$, Xilinhot, Inner Mongolia, China (Fig. 1a). The climate is temperate and semi-arid. The annual mean temperature is $0.2^{\circ} \mathrm{C}$. The annual precipitation is approximately $350 \mathrm{~mm}$. The dominant vegetation is typical of the steppes of the Inner Mongolia Plateau interspersed with sand dune complexes. The landforms include hills, lava tablelands and sandy lands, with an average elevation of $1,350 \mathrm{~m}$. A previous study in the area revealed accumulation of metals in $X P C$ due to sand-dust deposition [15].

$X P C$ was sampled in September 2012 from five sampling sites around the Inner Mongolia Grassland Ecosystem Research Station (IMGERS) of the Chinese Academy of Sciences. The sampling sites were selected at intervals of $4 \mathrm{~km}$ (Fig. 1b). All the sites were $>1 \mathrm{~km}$ from any major roads and settlements and $>0.5 \mathrm{~km}$ from any farms in order to minimize the effects of potential local anthropogenic emissions. Five samples $(n=1$ for each sampling site), each containing approximately 200 thalli, were placed in a paper bag and numbered for processing.

Five controls were selected, each consisting of 15-20 randomly selected thalli taken from each of the five samples. In the subsequent process, the five samples were mixed together, from which 20 transplants were selected. Each transplant consisted of 15-20 randomly selected thalli. The controls and transplants were carefully cleaned under a low-magnification stereo microscope. The transplants were placed in a nylon net bag and immediately transported to the exposure sites. The controls were kept in sealed paper bags at room temperature until analysis.

\section{Sample Exposure}

The exposure experiment started on October 1, 2012, and ended after 12 months. A $4.6 \mathrm{~km}$-long transect was selected. The transect is located in a suburban area between the downtown regions of Baoding $(7 \mathrm{~km}$ to the south of the transect) and Xushui (7 km to the north of the transect; Fig. 1c). The area is flat with an altitude of approximately $20 \mathrm{~m}$. Both cities have populations of over 1 million and are surrounded by dense villages. The G4 expressway is located at the east end of the transect, and the G107 highway (adjacent to a railway) is located at the west end (Fig. 1c). Each of the two roads had a mean traffic intensity of over 20,000 vehicles per day during the exposure period.

Five exposure sites (A, B, C, D, and E) were selected symmetrically to the centre of the transect, and their distances from the nearest road were 500 $\mathrm{m}, 1000 \mathrm{~m}, 2300 \mathrm{~m}, 1000 \mathrm{~m}$ and $500 \mathrm{~m}$, respectively (Fig. 1d). On October 1, 2012, the lichen transplants (in the $8 \times 10 \mathrm{~cm}$ nylon net bags) were attached to the branches of Populus trees at approximately 2-3 m above the soil. A total of 20 transplants were exposed, with 4 transplants positioned at each of the 5 exposure sites. One composite sample at each exposure site was retrieved at intervals of 3 months. To minimize heterogeneity among bags, the composite sample (15-20 thalli, 5.0-7.0 g) was a mixture of thalli randomly taken from 4 bags (3-5 thalli per bag). The retrieved samples were sealed in plastic bags and designated based on 
a combination of the exposure site and exposure time (Fig. 1e).

\section{Meteorological and Pollution Conditions during Exposure}

According to data from a weather station in the vicinity $(7 \mathrm{~km})$ of the exposure sites, the total precipitation during the exposure period was $614 \mathrm{~mm}$, and $81 \%$ of the precipitation occurred as rainfall from June to September of 2013 (Fig. 1f). The region experienced severe air pollution during the exposure period, particularly in the form of aerosol smog, which occurs frequently in winter [6]. Fig. 1g) shows that the highest concentrations of atmospheric $\mathrm{SO}_{2}, \mathrm{PM}_{2.5}$ and $\mathrm{PM}_{10}$ occurred from December 2012 to March 2013. The primary contributors to air pollution in the region are anthropogenic emissions. For example, one of the largest sources of atmospheric $S$ and particulate matter is the emissions from residential fossil fuel combustion, especially coal combustion during the winter heating period (from November 15 to March 15). Local anthropogenic activities, including intensive industrial operations, agricultural practices and traffic, may also be important contributors. Because Hebei Province is one of the most polluted provinces in China [5-6], the long-distance transport of air pollutants might also be an important source. In addition, the emissions from the two roads should be considered because both roads are among the busiest roads in China.

\section{Sample Preparation and Measurement}

All samples were cleaned under a low-magnification stereomicroscope in order to remove extraneous materials and then dried at $70^{\circ} \mathrm{C}$ for $72 \mathrm{~h}$ in a drying oven to a constant weight. The samples were ground and homogenized in a grinding mill equipped with tungsten carbide jars (Retsch MM400; Retsch GmbH, Haan, Germany) and sieved through a mesh with a pore size of $2 \mathrm{~mm}$. A 200-300 mg sample was mineralized in a mixture of $\mathrm{HNO}_{3}$ and $\mathrm{H}_{2} \mathrm{O}_{2}$. The concentrations of 25
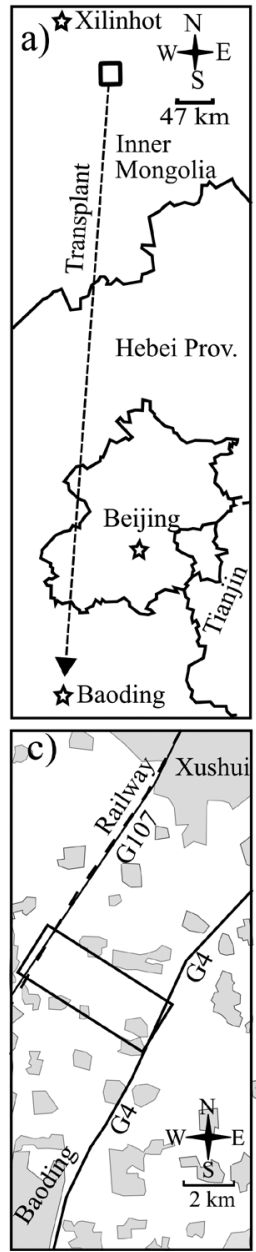
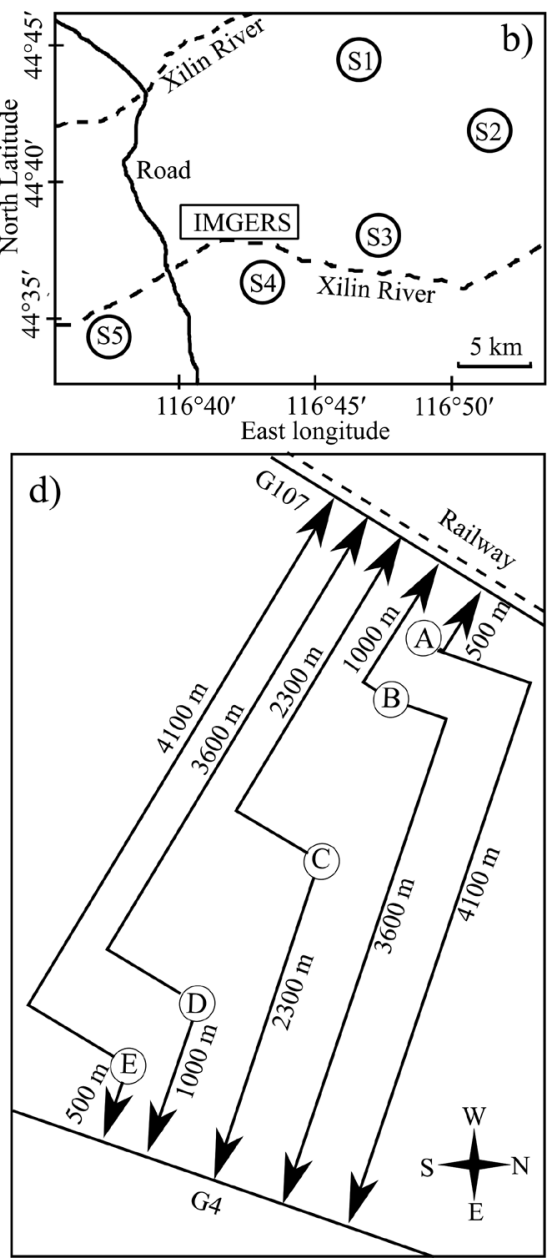
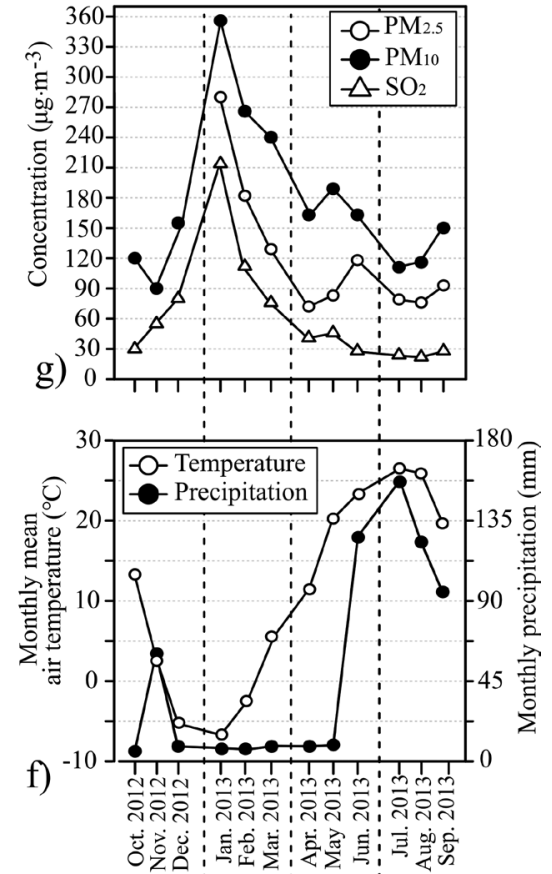

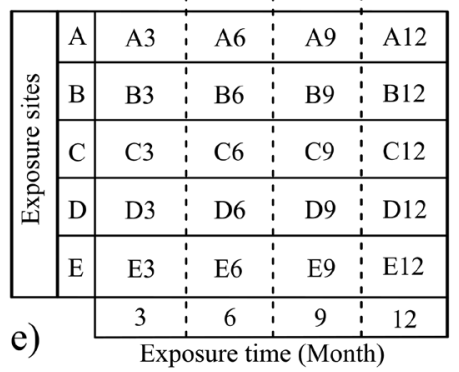

Fig. 1. Experimental design and meteorological and pollution conditions in Baoding during the exposure period: a) locations of the initial and exposure sites (stars indicate cities and the block indicates the sampling site); b) collection sites around IMGERS (Inner Mongolian Grassland Ecosystem Research Station), CAS; c) transect (the grey area indicates residential sites); d) exposure sites; e) numbering of the exposure samples; f) monthly mean air temperatures and monthly precipitation during exposure; and g) concentration of air pollutants during exposure. 
elements (Al, Ba, Cd, Ce, Cs, Cu, Fe, La, Mg, Mn, Na, $\mathrm{Ni}, \mathrm{Pb}, \mathrm{Rb}, \mathrm{S}, \mathrm{Sb}, \mathrm{Sc}, \mathrm{Sm}, \mathrm{Sr}, \mathrm{Tb}, \mathrm{Th}, \mathrm{Ti}, \mathrm{Tl}, \mathrm{V}$, and $\mathrm{Zn}$ ) were measured using an inductively coupled plasma mass spectrometer (ICP-MS; Agilent 7700X; Agilent Technologies, Tokyo, Japan) at the Hebei Research Center for Geoanalysis.

Quality control of the ICP-MS results was ensured by conducting simultaneous analyses of a series of standard reference materials (SRMs): IAEA-336 (Portuguese lichen, issued by the International Atomic Energy Agency), GBW10014 (cabbage), GBW10015 (spinach) and GBW10052 (green tea; all materials noted above were issued by the Institute of Geophysical and Geochemical Exploration, Chinese Academy of Geological Sciences). The analytical precision and accuracy are generally $<10 \%$ for most elements. These methods have been published elsewhere [16-17].
EC Ratio and PLI $\mathrm{I}_{\text {site }}$

The exposed-to-control (EC) ratio is the ratio between the POST-c (element concentration of a postexposure sample) and the corresponding control element concentration value. This parameter is a measure of the accumulation rate, with an EC ratio of $>1.75$ indicating "severe accumulation" [18-19]. The EC ratio is widely used as a method for determining the spatial patterns and temporal trends for element accumulation in lichen transplants [4, 8, 11, 20-21].

The PLI (pollutant loading index) is a comprehensive proxy for categorizing the degree of pollution based on several metals in certain sites or areas [22]. This parameter has been used in relevant biomonitoring studies employing lichens or mosses.

Table 1. Element concentrations in Xanthoparmelia camtschadalis.

\begin{tabular}{|c|c|c|c|c|c|c|c|c|c|}
\hline \multirow{2}{*}{ Group } & \multirow{2}{*}{ Subgroup } & \multirow{2}{*}{ Element } & \multicolumn{2}{|c|}{ Control $\left(\mu \mathrm{g} \mathrm{g}^{-1}\right)$} & \multicolumn{5}{|c|}{ Post-exposure $\left(\mu \mathrm{g} \mathrm{g}^{-1}\right)$} \\
\hline & & & Mean & $\mathrm{CV}(\%)$ & Minimum & $\mathrm{P}-25$ & Median & P-75 & Maximum \\
\hline & & $\mathrm{S}$ & 1008 & 24.37 & 2269 & 2750 & 3769 & 5124 & 6415 \\
\hline \multirow{24}{*}{ II } & \multirow{20}{*}{ IIa } & $\mathrm{Al}$ & 2888 & 21.81 & 3781 & 4822 & 6833 & 12748 & 19205 \\
\hline & & $\mathrm{Ba}$ & 30.02 & 8.34 & 43.06 & 59.70 & 103.6 & 170.7 & 246.2 \\
\hline & & $\mathrm{Ce}$ & 6.732 & 30.51 & 7.648 & 11.62 & 14.59 & 23.32 & 29.33 \\
\hline & & Cs & 0.570 & 27.27 & 0.583 & 0.750 & 1.020 & 1.806 & 2.773 \\
\hline & & $\mathrm{Cu}$ & 4.954 & 14.50 & 9.443 & 14.69 & 20.00 & 33.23 & 44.03 \\
\hline & & $\mathrm{Fe}$ & 1820 & 24.01 & 2282 & 4015 & 5901 & 10055 & 14253 \\
\hline & & $\mathrm{La}$ & 3.858 & 32.43 & 3.747 & 6.286 & 7.983 & 12.62 & 16.14 \\
\hline & & $\mathrm{Mg}$ & 903.3 & 11.88 & 979.3 & 1341 & 1859 & 3137 & 4418 \\
\hline & & $\mathrm{Mn}$ & 55.32 & 14.67 & 95.39 & 153.0 & 201.9 & 302.4 & 496.7 \\
\hline & & $\mathrm{Na}$ & 421.0 & 20.71 & 565.2 & 775.0 & 1187 & 2067 & 4184 \\
\hline & & $\mathrm{Ni}$ & 2.686 & 13.06 & 6.534 & 8.867 & 10.39 & 14.18 & 17.82 \\
\hline & & $\mathrm{Rb}$ & 7.883 & 21.51 & 7.424 & 9.801 & 13.57 & 20.56 & 36.98 \\
\hline & & $\mathrm{Sc}$ & 0.358 & 34.32 & 0.342 & 0.475 & 0.773 & 1.785 & 3.277 \\
\hline & & $\mathrm{Sm}$ & 0.489 & 32.57 & 0.585 & 0.816 & 1.027 & 1.627 & 2.064 \\
\hline & & $\mathrm{Sr}$ & 43.65 & 19.02 & 31.25 & 54.79 & 71.97 & 85.16 & 120.1 \\
\hline & & $\mathrm{Tb}$ & 0.069 & 38.73 & 0.088 & 0.111 & 0.129 & 0.198 & 0.247 \\
\hline & & Th & 0.591 & 39.78 & 0.778 & 0.970 & 1.386 & 2.492 & 3.123 \\
\hline & & $\mathrm{Ti}$ & 159.5 & 27.10 & 141.9 & 205.9 & 291.6 & 487.9 & 745.9 \\
\hline & & $\mathrm{Tl}$ & 0.077 & 21.88 & 0.133 & 0.185 & 0.257 & 0.339 & 0.483 \\
\hline & & V & 4.181 & 21.34 & 5.044 & 8.113 & 13.20 & 22.39 & 32.58 \\
\hline & \multirow{4}{*}{$\mathrm{IIb}$} & $\mathrm{Cd}$ & 0.258 & 11.53 & 0.482 & 0.738 & 0.982 & 1.416 & 1.924 \\
\hline & & $\mathrm{Pb}$ & 6.989 & 16.28 & 10.90 & 36.40 & 75.77 & 94.08 & 183.2 \\
\hline & & $\mathrm{Sb}$ & 0.123 & 22.61 & 0.536 & 0.782 & 1.088 & 1.738 & 2.981 \\
\hline & & $\mathrm{Zn}$ & 38.73 & 24.18 & 51.99 & 98.92 & 143.7 & 189.6 & 293.8 \\
\hline
\end{tabular}


Usually, a PLI of $>4$ indicates "high pollution" and $>5$ indicates "extreme pollution"[22-23]. The PLI at a particular site is recorded as $\mathrm{PLI}_{\text {site }}$, which is calculated as follows:

$$
\mathrm{PLI}_{\text {site }}=\left(\mathrm{CF}_{1} \times \mathrm{CF}_{2} \times \mathrm{CF}_{3} \times \ldots . . \times \mathrm{CF}_{\mathrm{n}}\right)^{1 / \mathrm{n}}
$$

$\mathrm{CF}_{\mathrm{n}}$ is the contamination factor of element $\mathrm{n}$, and $\mathrm{n}$ is the number of elements considered. In this study, the EC ratio was used instead of the CF.

\section{Statistical Analyses}

The control concentration and POST-c results for each element in $X P C$ were tested for normality using the Shapiro-Wilk test. Because the control concentration values were normally distributed $(p>0.05)$, the mean and coefficient of variation $(\mathrm{CV})$ are presented for each element. The differences between each POST-c and control concentration were tested using the one-sample t-test. A five-number summary (minimum, P25, median, P75 and maximum) is provided for the POST-c and EC ratio of each element because they were typically not normally distributed $(p<0.05)$. The POST-c values and the means of the control samples were included in the cluster and heatmap analyses. A cluster analysis was conducted using the correlation coefficient and the average link (UPGMA) algorithm. A heatmap analysis was conducted on the log2-transformed concentrations. Statistical analyses were performed using PAST 3.20 software (Ø. Hammer, April 2018), and plots were drawn using Inkscape 0.92 software (Free Software Foundation Inc., USA).

\section{Results}

\section{Element Concentrations, EC Ratios and PLI $\mathrm{I}_{\text {site }}$ Values}

Table 1 shows the statistics for the control concentrations and POST-c results. The CVs for the control concentrations were $<15 \%$ for 6 of the metals ( $\mathrm{Ba}, \mathrm{Cd}, \mathrm{Cu}, \mathrm{Mg}, \mathrm{Mn}$, and $\mathrm{Ni}$ ) and $16-40 \%$ for the other elements. The order of the mean concentrations in the control samples was as follows: $\mathrm{Al}>\mathrm{Fe}>\mathrm{S}>\mathrm{Mg}>\mathrm{Na}>\mathrm{Ti}>$ $\mathrm{Mn}>\mathrm{Sr}>\mathrm{Zn}>\mathrm{Ba}>\mathrm{Rb}>\mathrm{Pb}>\mathrm{Ce}>\mathrm{Cu}>\mathrm{V}>\mathrm{La}>\mathrm{Ni}>\mathrm{Th}>\mathrm{Cs}>$ $\mathrm{Sm}>\mathrm{Sc}>\mathrm{Cd}>\mathrm{Sb}>\mathrm{Tl}>\mathrm{Tb}$. This order was roughly similar to that of the POST-c values; however, 6 of the metals $(\mathrm{Ba}, \mathrm{Cu}, \mathrm{Ni}, \mathrm{Pb}, \mathrm{Sb}$ and $\mathrm{Zn}$ ) were ranked higher than expected from their ranks in the control samples.

The concentration correlations between the elements were well represented by a UPGMA cluster analysis on a correlation matrix of 21 samples (1 mean of the control concentrations +20 POST-c values), as suggested by a cophenetic correlation index of 0.9799 . Two groups were identified at a correlation similarity of 0.50 (Fig. 2a). Group I consisted of S. Group II consisted of metals.
Two subgroups could be identified at a correlation similarity of 0.75 . Subgroup IIa consisted of 20 metals (Al, Ba, Ce, Cs, Cu, Fe, La, Mg, Mn, Na, Ni, Rb, $\mathrm{Sc}, \mathrm{Sm}, \mathrm{Sr}, \mathrm{Tb}, \mathrm{Th}, \mathrm{Ti}, \mathrm{Tl}$, and V), and subgroup IIb consisted of 4 metals (Cd, Pb, Sb, and $\mathrm{Zn}$ ) (Fig. 2a).

Table 2 shows the EC and the $\mathrm{PLI}_{\text {site }}$ results. Most elements had a median EC of 1.65-4.04, except $\mathrm{Pb}$ $(\mathrm{EC}=10.84)$ and $\mathrm{Sb}(\mathrm{EC}=8.82)$. The median $\mathrm{PLI}_{\text {site }}$ was 2.84 for all the metals detected, 2.44 for the subgroup IIa metals and 6.26 for the subgroup IIb metals.

\section{Spatial-Temporal Patterns}

The differences between the control concentration and POST-c for each element and their spatialtemporal patterns are shown in Fig. 2b). At all sites, the concentrations of $\mathrm{S}$ were significantly higher than the control values (one-sample t-test; $p<0.01$ ) and showed a unimodal curve with a peak concentration at 6 months of exposure.

Most of the POST-c values of the metals were higher than the control concentrations (one-sample t-test, $p<0.05$; Fig. 2b). At each exposure time, the subgroup IIa and IIb metals had similar spatial patterns characterized by higher concentrations at sites $\mathrm{A}$ and $\mathrm{E}$ relative to the other sites. However, the two subgroups did not have similar temporal trends. The concentrations of the subgroup IIa metals did not always increase immediately after exposure and showed generally increasing trends over the exposure time at all sites. For example, the concentrations of four metals $(\mathrm{Cs}, \mathrm{Rb}, \mathrm{Sr}$, and $\mathrm{Ti}$ ) at three exposure sites (A, B, and $\mathrm{C}$ ) were not significantly higher than the control values after 3-month exposure (one-sample t-test, $\alpha=0.05$ ), but reached their peak after 12-month exposure at most sites (Fig. 2b). In contrast, the concentrations of the subgroup IIb metals were significantly higher than the control values after the 3-month exposure (one-sample t-test, all significant at $p<0.05$ ) and showed a unimodal concentration curve with a peak at the 9-month exposure. These results were prominent in the PLI ${ }_{\text {site }}$ patterns (Fig. 2b).

\section{Discussion}

\section{Comparison with Other Studies}

Our results suggest severe air pollution at the exposure sites. A comparison with the relevant studies shows that the median values for the POST-cs of most elements in $X P C$ were higher than the documented values from "clean sites" $[9,12,20,24-26]$ and "polluted sites" $[15,27-28]$. This conclusion is consistent with the results of instrumental air quality monitoring (Fig. 1g) and the diverse and heavy emissions detailed in the section "Meteorological and pollution conditions during exposure". Most elements had median EC ratios of $>1.75$ (Table 2), and the subgroup IIb metals had median PLI ${ }_{\text {site }}$ values $>5$, corresponding to a "severe accumulation 
Table 2. Exposed-to-control (EC) ratio and pollutant loading index at site ( $\mathrm{PLI}_{\text {site }}$ ) of the elements in Xanthoparmelia camtschadalis $(X P c)$.

\begin{tabular}{|c|c|c|c|c|c|c|c|}
\hline \multirow{2}{*}{ Group } & \multirow{2}{*}{ Subgroup } & \multirow{2}{*}{ Element } & \multicolumn{5}{|c|}{ Exposed-to-control ratio } \\
\hline & & & Minimum & $\mathrm{P}-25$ & Median & P-75 & Maximum \\
\hline \multicolumn{2}{|c|}{ I } & $\mathrm{S}$ & 2.25 & 2.73 & 3.74 & 5.08 & 6.36 \\
\hline \multirow{26}{*}{ II } & \multirow{20}{*}{ IIa } & $\mathrm{Al}$ & 1.31 & 1.67 & 2.37 & 4.41 & 6.65 \\
\hline & & $\mathrm{Ba}$ & 1.43 & 1.99 & 3.45 & 5.69 & 8.20 \\
\hline & & $\mathrm{Ce}$ & 1.14 & 1.73 & 2.17 & 3.46 & 4.36 \\
\hline & & Cs & 1.02 & 1.32 & 1.79 & 3.17 & 4.86 \\
\hline & & $\mathrm{Cu}$ & 1.91 & 2.96 & 4.04 & 6.71 & 8.89 \\
\hline & & $\mathrm{Fe}$ & 1.25 & 2.21 & 3.24 & 5.53 & 7.83 \\
\hline & & $\mathrm{La}$ & 0.97 & 1.63 & 2.07 & 3.27 & 4.18 \\
\hline & & $\mathrm{Mg}$ & 1.08 & 1.48 & 2.06 & 3.47 & 4.89 \\
\hline & & $\mathrm{Mn}$ & 1.72 & 2.77 & 3.65 & 5.47 & 8.98 \\
\hline & & $\mathrm{Na}$ & 1.34 & 1.84 & 2.82 & 4.91 & 9.94 \\
\hline & & $\mathrm{Ni}$ & 2.43 & 3.30 & 3.87 & 5.28 & 6.63 \\
\hline & & $\mathrm{Rb}$ & 0.94 & 1.24 & 1.72 & 2.61 & 4.69 \\
\hline & & $\mathrm{Sc}$ & 0.96 & 1.33 & 2.16 & 4.99 & 9.16 \\
\hline & & $\mathrm{Sm}$ & 1.20 & 1.67 & 2.10 & 3.33 & 4.22 \\
\hline & & $\mathrm{Sr}$ & 0.72 & 1.26 & 1.65 & 1.95 & 2.75 \\
\hline & & $\mathrm{Tb}$ & 1.27 & 1.61 & 1.86 & 2.86 & 3.57 \\
\hline & & Th & 1.32 & 1.64 & 2.34 & 4.21 & 5.28 \\
\hline & & $\mathrm{Ti}$ & 0.89 & 1.29 & 1.83 & 3.06 & 4.68 \\
\hline & & $\mathrm{Tl}$ & 1.73 & 2.39 & 3.34 & 4.39 & 6.26 \\
\hline & & $\mathrm{V}$ & 1.21 & 1.94 & 3.16 & 5.36 & 7.79 \\
\hline & \multicolumn{2}{|c|}{ Pollutant loading index at site } & 1.29 & 1.86 & 2.44 & 3.93 & 5.82 \\
\hline & \multirow{4}{*}{$\mathrm{IIb}$} & $\mathrm{Cd}$ & 1.87 & 2.86 & 3.80 & 5.48 & 7.45 \\
\hline & & $\mathrm{Pb}$ & 1.56 & 5.21 & 10.84 & 13.46 & 26.22 \\
\hline & & $\mathrm{Sb}$ & 4.35 & 6.34 & 8.82 & 14.10 & 24.18 \\
\hline & & $\mathrm{Zn}$ & 1.34 & 2.55 & 3.71 & 4.90 & 7.59 \\
\hline & \multicolumn{2}{|c|}{ Pollutant loading index at site } & 2.03 & 3.97 & 6.26 & 7.69 & 13.76 \\
\hline \multicolumn{3}{|c|}{ Pollutant loading index at site } & 1.39 & 2.04 & 2.84 & 4.56 & 6.33 \\
\hline
\end{tabular}

level" [18] and "very high pollution" [22], respectively, providing additional evidence of severe air pollution.

\section{Sulfur}

The results of the clustering analysis (Fig. 2a) clearly show that $\mathrm{S}$ had a spatial-temporal pattern that was different from those of the metals. This difference in spatial-temporal pattern between $\mathrm{S}$ and metals is further illustrated by the heat maps (Fig. 2b). In general, the concentration of $\mathrm{S}$ followed a unimodal curve with a peak after 6 months of exposure at all the exposure sites regardless of their distances from roads. This temporal trend is similar to that of atmospheric $\mathrm{SO}_{2}$ concentration, which was highest in January-March of $2013\left(76-214 \mu \mathrm{g} \mathrm{m}^{-3}\right)$, followed by NovemberDecember of $2012\left(30-80 \mu \mathrm{g} \mathrm{m}^{-3}\right)$, April-June of 2013 (28-41 $\left.\mu \mathrm{g} \quad \mathrm{m}^{-3}\right)$ and June-September of 2013 (22-28 $\mu \mathrm{g} \mathrm{m}^{-3}$; Fig. $\left.1 \mathrm{~g}\right)$.

The similar temporal trends of lichen $\mathrm{S}$ and atmospheric $\mathrm{SO}_{2}$ indicate that the major source of atmospheric $\mathrm{S}$ deposition during the heating period was $\mathrm{SO}_{2}$. In recent decades, coal combustion has been the dominant energy source for domestic cooking and 
heating, and the associated heaters are not usually fitted with particulate material and $\mathrm{SO}_{2}$ control devices [5]. Severe air pollution events occur frequently in China during the winter heating period, particularly in the form of aerosol smog [6]. Previous studies reported that the $\mathrm{SO}_{2}$ uptake rate of lichens is positively correlated with the ambient $\mathrm{SO}_{2}$ level [29], and air pollution in urban and industrial sites reportedly resulted in increased lichen $\mathrm{S}$ concentrations [7, 30].

These results also reflect the short $\mathrm{SO}_{2}$ integration time of $X P c$. Integration time, also known as memory length or remembrance time, is an expression of the time over which the preceding environmental availability is reflected by the lichen elemental concentrations [31, 32]. Integration time is one of the most important issues in transplantation method because an exposure time shorter than the integration time would seriously hamper the assessment of current levels of atmospheric pollutants. The sharp increase of lichen S during the winter heating period and the subsequent rapid decrease (Fig. 2b) clearly show that $X P C$ had an integration time of $<3$ months for $\mathrm{SO}_{2}$. The rapid reduction in lichen $\mathrm{S}$ after the heating period may be attributable to a coupling of leaching effects of increased rainfall (126 mm, Fig. 1f) and decreased atmospheric $\mathrm{SO}_{2}$ concentration in June 2013 (Fig. 1g).

\section{Metals}

Road traffic has been identified as an important source of atmospheric metals, which could be released from the abrasion and corrosion of automobile parts, vehicle exhausts, and road dust suspension [1, 3, 25, 33]. As a result, many studies have reported increasing metal accumulation in lichens with increasing proximity to roads $[13,24,34]$. The present study also found that the metal concentrations in $X P C$ were highly affected by roads emissions and exposure time. At each exposure

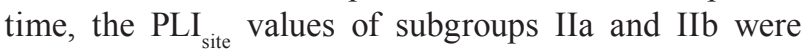
higher at the sites near roads (sites $\mathrm{A}$ and $\mathrm{E}$ ) than those at sites $\mathrm{B}$ and $\mathrm{C}$, and generally increased with increasing exposure time (Fig. 2b).

Vascular plants were also used as biomonitors of atmospheric element deposition [4]. Comparable results between lichens and vascular plants would be expected because authors observed a good positive correlation between the two taxa for many elements [35-36]. The metal concentration trends in the present study were also observed in previous studies using vascular plants as biomonitors. For example, concentrations of 15 metals in leaves of lettuce (Lactuca sativa cv. Romaine) were higher in the urban areas with greater traffic intensity than in the rural ones [37]. Hassan et al. used date palm (Phoenix dactylifera) as a biomonitor, and found that concentrations of measured 12 elements were higher in the urban site than in the residential one and increased with the harvest time [38].

The two subgroups (IIa and IIb) apparently had different temporal trends. At the two sites near roads (A and E, Fig. 2b), the concentrations and PLI ${ }_{\text {site }}$ values of the subgroup IIb metals reached their peak at 9 months of exposure, whereas those of the subgroup IIa metals
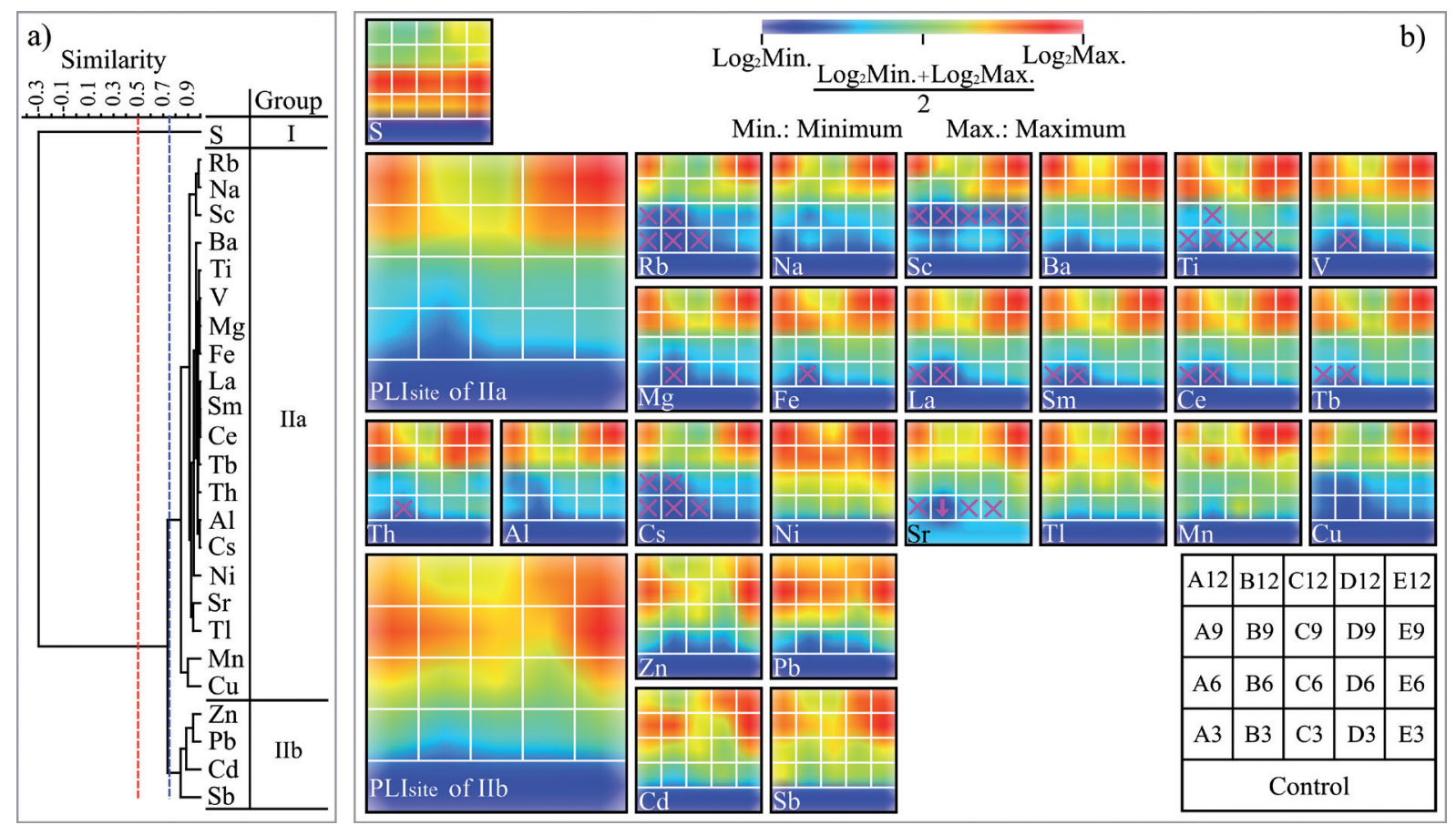

Fig. 2. UPGMA cluster analysis (a) and the spatial-temporal patterns of element concentrations and $\mathrm{PLI}_{\text {site }}$ (b); the broken red and blue lines in the diagram show correlation similarities of 0.50 and 0.75 , respectively, while " $\times$ " and " $\downarrow$ " indicate that the POST-c is not significantly different from and significantly lower than the control, respectively. 
peaked at 12 months of exposure (Fig. 2b). These results suggest that the $X P c$ exhibited preferential uptake and/or retention of certain metals. Another possible explanation for these results is the relative contributions of vehicle emissions and roadside dust resuspension. In most relevant studies, the subgroup IIb metals $(\mathrm{Cd}, \mathrm{Pb}, \mathrm{Sb}$ and $\mathrm{Zn}$ ) were common traffic-related metals, and their accumulation in lichens near roads has been attributed to vehicle emissions [8, 24, 26, 34, 39]. In contrast, many subgroup IIa metals, such as $\mathrm{Rb}, \mathrm{Sc}, \mathrm{Ti}, \mathrm{Al}, \mathrm{Sr}$, $\mathrm{Tl}$, and lanthanides ( $\mathrm{La}, \mathrm{Sm}, \mathrm{Ce}$ and $\mathrm{Tb}$ ), have been regarded as terrigenous metals in many relevant studies [1-2]. Certain other metals in subgroup IIa are also traffic-related elements, such as $\mathrm{V}, \mathrm{Fe}, \mathrm{Ni}$ and $\mathrm{Cu}$ [1]. These results suggest roadside dust resuspension that includes soil dust mixed with traffic-related particles.

The integration time for these metals in $X P C$ was obviously longer than that for $\mathrm{SO}_{2}$. First, in the initial 3 months of exposure, the concentrations of certain metals (especially $\mathrm{Cs}, \mathrm{Rb}, \mathrm{Sr}$, and $\mathrm{Ti}$ ) were similar to or even lower than those of the control. This pattern was also observed in the 6-month exposures (Cs and Sc; Fig. 2b). Second, the concentration trends for most of the metals over the whole exposure period (Fig. 2b) were inconsistent with those of the atmospheric particles $\left(\mathrm{PM}_{2.5}\right.$ and $\mathrm{PM}_{10}$; Fig. 1g). These results suggest that the lichens had integration times of $>3$ months for these metals, which are close to the documented lichen integration time of $>2$ months for metals [32].

\section{Conclusions}

The median EC ratios of $>1.75$ for most elements

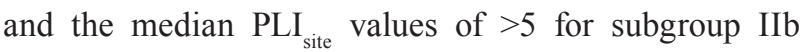
metals in Xanthoparmelia camtschadalis clearly indicate that the exposure sites were highly affected by atmospheric deposition. The similar concentration trends between lichen $\mathrm{S}$ and atmospheric $\mathrm{SO}_{2}$ suggest a predominant source of $\mathrm{SO}_{2}$ during the winter heating period in the region. The faster increase in lichen metal concentrations at sites near roads clearly shows the high impact of road emissions on atmospheric deposition. These results also indicate that this lichen can be used to measure short-term changes in atmospheric $\mathrm{SO}_{2}$ (<3 months) and longer-term trends in atmospheric metals ( $>3$ months). Overall results validated the applicability of $X P C$ in the transplantation method for assessing the degree of air pollution near roads.

\section{Acknowledgments}

The authors would like to thank the National Key Research and Development Program (grant No. 2016YFC0500700), the National Natural Science Foundation of China (No. 31000239), the Natural Science Foundation of Hebei Province (Nos C2014201032 and
C2010000268), the Key Bioengineering Discipline of Hebei Province (No. 1050-5030023) and the Key Laboratory of Microbial Diversity Research and Application of Hebei Province for their financial support.

\section{Conflict of Interest}

The authors declare no conflict of interest.

\section{References}

1. GARTY J. Biomonitoring atmospheric heavy metals with lichens: Theory and application. Crit. Rev. Plant Sci., 20 (4), 309, 2001.

2. NASHIII T.H. Lichen Biology, $2^{\text {nd }}$ ed.; Cambridge University Press, Cambridge, UK, 486, 2008.

3. SUJETOVIENE G. Monitoring lichen as indicators of atmospheric quality. In Recent advances in lichenology, UPRETI D., DIVAKAR P., SHUKLA V., BAJPAI R., Eds., Springer India: New Delhi, 87, 2015.

4. BRUNIALTI G., FRATI L. Bioaccumulation with lichens: the Italian experience. Int. J. Environ. Stud., 71 (1), 15, 2014.

5. TIAN H.Z., ZHU C.Y., GAO J.J., CHENG K., HAO J.M., WANG K., HUA S.B., WANG Y., ZHOU J.R. Quantitative assessment of atmospheric emissions of toxic heavy metals from anthropogenic sources in China: historical trend, spatial variation distribution, uncertainties and control policies. Atmos. Chem. Phys., 15 (8), 12107, 2015.

6. WANG L.T., YANG J., ZHANG P., ZHAO X.J., WEI Z., ZHANG F.F., SU J., MENG C.C. A review of air pollution and control in Hebei Province, China. Open Journal of Air Pollution, 2 (3), 47, 2013.

7. PAOLI L., WINKLER A., GUTTOVÁ A., SAGNOTTI L., GRASSI A., LACKOVIČOVÁ A., SENKO D., LOPPI S. Magnetic properties and element concentrations in lichens exposed to airborne pollutants released during cement production. Environ. Sci. Pollut. R., 24 (3), 1, 2016.

8. VANNINI A., PAOLI L., NICOLARDI V., Di LELLA L.A., LOPPI S. Seasonal variations in intracellular trace element content and physiological parameters in the lichen Evernia prunastri transplanted to an urban environment. Acta Bot. Croat., 76 (2), 171, 2017.

9. ACHOTEGUI-CASTELLS A., SARDANS J., RIBAS À.,PEÑUELAS J. Identifying the origin of atmospheric inputs of trace elements in the Prades Mountains (Catalonia) with bryophytes, lichens, and soil monitoring. Environ. Monit. Assess., 185 (1), 615, 2013.

10. AGNAN Y., PROBST A., SÉJALON-DELMAS N. Evaluation of lichen species resistance to atmospheric metal pollution by coupling diversity and bioaccumulation approaches: A new bioindication scale for French forested areas. Ecol. Indic., 72, 99, 2017.

11. MALASPINA P., GIORDANI P., MODENESI P., ABELMOSCHI M.L., MAGI E., SOGGIA F. Bioaccumulation capacity of two chemical varieties of the lichen Pseudevernia furfuracea. Ecol. Indic., 45, 605, 2014.

12. SINGH S.M., SHARMA J., GAWAS-SAKHALKAR P., UPADHYAY A.K., NAIK S., PEDNEKER S.M., 
RAVINDRA R. Atmospheric deposition studies of heavy metals in Arctic by comparative analysis of lichens and cryoconite. Environ. Monit. Assess., 185 (2), 1367, 2013.

13. KURNAZ K., COBANOGLU G. Biomonitoring of air quality in Istanbul Metropolitan Territory with epiphytic lichen Physcia adscendens (Fr.) Olivier. Fresen. Environ. Bull., 26, 7296, 2017.

14. MALASPINA P., MODENESI P., GIORDANI P. Physiological response of two varieties of the lichen Pseudevernia furfuracea to atmospheric pollution. Ecol. Indic., 86, 27, 2018.

15. LIU H.J., FANG S.B., LIU S.W., ZHAO L.C., GUO X.P., JIANG Y.J., HU J.-S., LIU X.D., XIA Y., WANG Y.D., WU Q.F. Lichen elemental composition distinguishes anthropogenic emissions from dust storm input and differs among species: evidence from Xilinhot, Inner Mongolia, China. Sci. Rep.-UK., 6, 34694, 2016.

16. ZHAO L.C., JIANG Y.J., GUO X.P., LI X., WANG Y.D., GUO X.B., LU F., LIU H.J. Optimization of ICP-AES and ICP-MS techniques for the determination of major, minor and micro elements in lichens. Spectrosc. Spect. Anal., 36 (10), 3320, 2016.

17. ZHAO L.C., WANG L., JIANG Y.J., HU Y.Q., XU C.Y., WANG L., LI X., GUO X.P., LIU A.Q., LIU H.J. Determination of elemental concentrations in lichens using ICP-AES/MS. Bio-protocol, 7 (5), e2165, 2017.

18. FRATI L., BRUNIALTI G., LOPPI S. Problems related to lichen transplants to monitor trace element deposition in repeated surveys: a case study from Central Italy. J. Atmos. Chem., 52 (3), 221, 2005.

19. FERNÁNDEZ J.A., CARBALLEIRA A. Evaluation of contamination, by different elements, in terrestrial mosses. Arch. Environ. Contam. Toxicol., 40 (4), 461, 2001.

20. INCERTI G., CECCONI E., CAPOZZI F., ADAMO P., BARGAGLI R., BENESPERI R., CARNIEL F.C., CRISTOFOLINI F., GIORDANO S., PUNTILLO D., SPAGNUOLO V., TRETIACH M. Infraspecific variability in baseline element composition of the epiphytic lichen Pseudevernia furfuracea in remote areas: implications for biomonitoring of air pollution. Environ. Sci. Pollut. R., 24 (9), 8004, 2017.

21. NANNONI F., SANTOLINI R., PROTANO G. Heavy element accumulation in Evernia prunastri lichen transplants around a municipal solid waste landfill in central Italy. Waste Manage., 43, 353, 2015.

22. ZHANG C., QIAO Q., PIPER J.D., HUANG B. Assessment of heavy metal pollution from a Fe-smelting plant in urban river sediments using environmental magnetic and geochemical methods. Environ. Pollut., 159 (10), 3057, 2011.

23. ALLAJBEU S., QARRI F., MARKU E., BEKTESHI L., IBRO V., FRONTASYEVA M.V., STAFILOV T., LAZO P. Contamination scale of atmospheric deposition for assessing air quality in Albania evaluated from most toxic heavy metal and moss biomonitoring. Air Qual. Atmos. Health, 10 (5), 1, 2016.

24. BAJPAI R., UPRETI D. Accumulation and toxic effect of arsenic and other heavy metals in a contaminated area of West Bengal, India, in the lichen Pyxine cocoes (Sw.) Nyl. Ecotox. Environ. Safe., 83, 63, 2012.

25. BOAMPONSEM L.K., FREITAS C.R.D., WILLIAMS D. Source apportionment of air pollutants in the Greater Auckland Region of New Zealand using receptor models and elemental levels in the lichen, Parmotrema reticulatum. Atmos. Pollut. Res., 8 (1), 101, 2017.

26. RATIER A., DRON J., REVENKO G., AUSTRUY A., DAUPHIN C.-E., CHASPOUL F., WAFO E. Characterization of atmospheric emission sources in lichen from metal and organic contaminant patterns. Environ. Sci. Pollut. R., 25 (9), 8364, 2018.

27. CAYIR A., COSKUN M., COSKUN M. Determination of atmospheric heavy metal pollution in Canakkale and Balikesir Provinces using lichen (Cladonia rangiformis) as a bioindicator. Bull. Environ. Contam. Toxicol., 79 (4), 367, 2007.

28. LIU H.J., ZHAO L.C., FANG S.B., LIU S.W., HU J.S., WANG L., LIU X.D., WU Q.-F. Use of the lichen Xanthoria mandschurica in monitoring atmospheric elemental deposition in the Taihang Mountains, Hebei, China. Sci. Rep.-UK., 6, 23456, 2016.

29. GRIES C., SANZ M.-J., ROMAGNI J.G., GOLDSMITH S., KUHN U., KESSELMEIER J., NASHIII T.H. The uptake of gaseous sulphur dioxide by non-gelatinous lichens. New Phytol., 135, 595, 1997.

30. BENNETT J.P., WRIGHT D.M. Element content of Xanthoparmelia scabrosa growing on asphalt in urban and rural New Zealand. Bryologist, 107 (4), 421, 2004.

31. REIS M.A., ALVES L.C., FREITAS M.C., Van OS B., WOLTERBEEK H.T. Lichens (Parmelia sulcata) time response model to environmental availability. Sci. Total Environ., 232, 105, 1999.

32. GODINHO R., WOLTERBEEK H.T., VERBURG T., FREITAS M. Bioaccumulation behaviour of transplants of the lichen Flavoparmelia caperata in relation to total deposition at a polluted location in Portugal. Environ. Pollut., 151 (2), 318, 2008.

33. BASAHI J.M., ISMAIL I.M., HASSAN I.A., ALMEELBI T., HAIBA N.S., HAMMAM E. Total suspended particulate matter (TSP) and its associated heavy metals in atmosphere on the Western Coast of Saudi Arabia. Pol. J. Environ. Stud., 26(5), 2419, 2017.

34. YEMETS O.A., SOLHAUG K.A., GAUSLAA Y. Spatial dispersal of airborne pollutants and their effects on growth and viability of lichen transplants along a rural highway in Norway. Lichenologist, 46 (6), 809, 2014.

35. BERLIZOV A., BLUM O., FILBY R., MALYUK I., TRYSHYN V. Testing applicability of black poplar (Populus nigra L.) bark to heavy metal air pollution monitoring in urban and industrial regions. Sci. Total Environ., 372 (2), 693, 2007.

36. PACHECO A., BARROS L., FREITAS M., REIS M., HIPÓLITO C., OLIVEIRA O. An evaluation of olivetree bark for the biological monitoring of airborne traceelements at ground level. Environ. Pollut., 120 (1), 79, 2002.

37. HASSAN I.A., BASAHI J.M. Assessing roadside conditions and vehicular emissions using roadside lettuce plants. Pol. J. Environ. Stud., 22 (2), 75, 2013.

38. HASSAN I.A., COTROZZI L., HAIBA N.S., BASAHI J.M., ISMAIL I.M., ALMEELBI T., HAMMAM E. Trace elements in the fruits of date palm (Phoenix dactylifera $\mathrm{L}$.) in Jeddah City, Saudi Arabia. Agrochimica,61 (1), 75, 2017.

39. AYRAULT S., CLOCHIATTI R., CARROT F., DAUDIN L., BENNETT J.P. Factors to consider for trace element deposition biomonitoring surveys with lichen transplants. Sci. Total Environ., 372 (2), 717, 2007. 
